Portland State University

PDXScholar

\title{
Surfactant-Free Hybridization of Transition Metal Oxide Nanoparticles With Conductive Graphene for High-Performance Supercapacitor
}

Wen Qian

Portland State University

Zhiqiang Chen

Portland State University

Steven Cottingham

Portland State University

William Alexander Merrill

Portland State University

Natasja A. Swartz

Portland State University

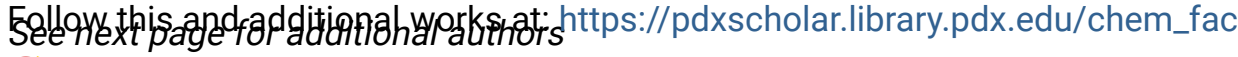

Part of the Materials Chemistry Commons

Let us know how access to this document benefits you.

\section{Citation Details}

Qian, W., Chen, Z., Cottingham, S., Swartz, N., Goforth, A., Clare, T., \& Jiao, J. (2012) Surfactant-Free Hybridization of Transition Metal Oxide Nanoparticles with Conductive Graphene for High-Performance Supercapacitor. Green Chemistry, 14, 2, 371-377.

This Article is brought to you for free and open access. It has been accepted for inclusion in Chemistry Faculty Publications and Presentations by an authorized administrator of PDXScholar. Please contact us if we can make this document more accessible: pdxscholar@pdx.edu. 


\section{Authors}

Wen Qian, Zhiqiang Chen, Steven Cottingham, William Alexander Merrill, Natasja A. Swartz, Andrea Goforth, Tami Lasseter Clare, and Jun Jiao 


\title{
Green Chemistry
}

Cite this: Green Chem., 2012, 14, 371

\section{Surfactant-free hybridization of transition metal oxide nanoparticles with conductive graphene for high-performance supercapacitor}

\author{
Wen Qian, ${ }^{a}$ Zhiqiang Chen, ${ }^{b}$ Steven Cottingham, ${ }^{a}$ William Alexander Merrill, ${ }^{c}$ Natasja A. Swartz, ${ }^{c}$ \\ Andrea Mitchell Goforth, ${ }^{c}$ Tami Lasseter Clare ${ }^{c}$ and Jun Jiao $* a, b$
}

Received 9th September 2011, Accepted 28th October 2011

DOI: 10.1039/c1gc16134b

In order to improve specific capacitance and limit electrical resistance, high-quality exfoliated graphene decorated with transition metal (Fe, Mn, Co) oxide nanoparticles (NPs) has been successfully synthesized without the use of surfactant via a simple, general, environmentallyfriendly chemical process. The specific capacitance of as-prepared graphene $/ \mathrm{Mn}_{3} \mathrm{O}_{4}$ composite reach $239.6 \mathrm{~F} / \mathrm{g}$, when employed as the anode material in neutral $\mathrm{NaCl}$ electrolyte solutions ( $c f$. 98.2 F/g for pristine graphene and $141.4 \mathrm{~F} / \mathrm{g}$ for pure $\mathrm{Mn}_{3} \mathrm{O}_{4} \mathrm{NPs}$ ), which indicate the synergetic effects from both graphene and attached $\mathrm{Mn}_{3} \mathrm{O}_{4}$ NPs. Moreover, the high conductivity of graphene eliminates the need for conductive carbon black as fillers. The current density of graphene $/ \mathrm{Mn}_{3} \mathrm{O}_{4}$ reached as high as $4.5 \mathrm{~A} \mathrm{~g}^{-1}$ which is much higher than that of graphene oxide (GO) or reduced GO-based composites. This significant enhancement of capacitance and current density was attributed to the surfactant-free approach to hybridize graphene with transition metal oxide NPs, the excellent conductivity of pristine graphene combined with its large surface area, as well as a uniform distribution of NPs on the clean surface of conductive graphene. Thus the low-toxicity, inexpensive graphene-based hybrids show promising utility as high current density electrode materials for supercapacitor applications.

\section{Introduction}

During the past few decades, transition metal oxide nanoparticles (NPs), such as $\mathrm{MnO}_{x}{ }^{1-3}$ and $\mathrm{Fe}_{3} \mathrm{O}_{4}{ }^{4,5}$ have been thoroughly explored as electrode materials for pseudocapacitors not only due to their prominent theoretical capacitance, but also due to their abundant and non-toxic elements. However, their high electrical resistance and poor electrochemical reversibility have limited their energy storage capacity in practical uses. Recently, carbon materials, such as activated carbon, carbon nanotube and graphene, have been shown as promising materials for electrochemical double layer capacitors. ${ }^{6-9}$ Due to its high specific surface area $\left(\sim 2600 \mathrm{~m}^{2} \mathrm{~g}^{-1}\right)^{10}$ and high electrical conductivity $\left(2 \times 10^{5} \mathrm{~cm}^{2} \mathrm{~V}^{-1} \mathrm{~s}^{-1}\right),{ }^{11,12}$ graphene can not only act as a substrate for good distribution of transition metal oxide NPs, but also as a direct conductive path for the rapid electron transmission. The one-step synthetic procedure we present serves to both

${ }^{a}$ Department of Physics, Portland State University, Portland, OR, 97201. E-mail: jiaoj@pdx.edu; Fax: (503) 725-2815; Tel: (503) 725-4228

${ }^{b}$ Center for Electron Microscopy and Nanofabrication, Portland State University, Portland, OR, 97201

'Department of Chemistry, Portland State University, Portland, OR, 97201 produce the transition metal oxide NPs and attach the NPs to the graphene surface. The procedure affords graphene based hybrids, which we demonstrated here, could potentially improve the energy storage capacity while limiting the energy losses due to electrical resistance.

Up to now, various methods have been developed to hybridize transition metal oxide NPs onto graphene oxide (GO) ${ }^{13-20}$ and onto carbon nanotubes, ${ }^{21-24}$ and these hybrids have been shown to act as promising electrode materials for supercapacitor applications. However all of these methods used GO or reduced GO as the precursor, and they are known to possess high densities of irreversible structural defects in their lattices. Another drawback of these potential supercapacitor materials is that the particle size and loading density of attached NPs cannot be precisely controlled. Moreover, these synthetic techniques require two or more complicated synthetic steps and additionally require the use of a surfactant. It is widely believed that the presence of surfactant or stabilizer in such hybrids hinders any improvement of the electrical properties of all kinds of graphene-based composites. Eliminating this surfactant or stabilizer between graphene sheets and their attached NPs should greatly improve both the charge-accumulating activity of the NPs and the electrical conductivity of the graphene substrate. The work presented here reveals a new strategy for the fabrication of 
graphene/metal oxide hybrids with no surfactant or stabilizer involved for the purpose of producing environmentally green graphene-based nanocomposites with high capacitances, high current densities, and excellent cycling stabilities.

High-quality graphene hybrid with attached magnetite $\left(\mathrm{Fe}_{3} \mathrm{O}_{4}\right)$ NPs were readily prepared using a simple solvothermal process. Iron(III) acetylacetonate and expanded graphite were employed as precursors, and ethanol was used as a safe and harmless reaction medium. Most importantly, no surfactant was involved in the preparation of these nanophase composite materials. Experimental results demonstrated that this simple and environmentally friendly chemical process could be extended to hybridize other metal oxide NPs, such as $\mathrm{Mn}_{3} \mathrm{O}_{4}$ and $\mathrm{CoO}$. In the present study, TEM analyses indicated that the particle size and coating density of $\mathrm{Fe}_{3} \mathrm{O}_{4}$ and $\mathrm{Mn}_{3} \mathrm{O}_{4}$ could be readily tailored by varying reaction time. The electrochemical performance of graphene $/ \mathrm{Mn}_{3} \mathrm{O}_{4}$, graphene $/ \mathrm{Fe}_{3} \mathrm{O}_{4}$, and graphene/CoO composites as supercapacitor anode materials was also investigated, and these hybrids were found to exhibit enhanced capacitance compared to that of pristine graphene and pure NPs. They also were shown to have high current density while maintaining longterm cycling stability.

\section{Experimental}

\section{Chemicals and materials}

1-Methyl-2-pyrrolidone (NMP) anhydrous, 99.5\% (SigmaAldrich); absolute, anhydrous ethyl alcohol (Pharmco-Aaper); Iron(III) acetylacetonate, $\mathrm{Fe}(\mathrm{acac})_{3}, 95 \%$ (Acros Organics); Manganese(III) acetylacetonate, $\mathrm{Mn}(\mathrm{acac})_{3}, 98 \%$ (Alfa Aesar); Cobalt(III) acetylacetonate, $\mathrm{Co}(\mathrm{acac})_{3}, 99.99 \%$ (Aldrich); polyvinylidenefluoride, PVDF, (Aldrich, powder, average M.W. -534000); expandable graphite (average diameter $300 \mu \mathrm{m}, 99 \%$ purity, Beijing Invention Biology Engineering \& New Material Co. Ltd., China); High density nickel foam $\left(3000 \mathrm{~g} \mathrm{~m}^{-2}\right.$, Heze Jiaotong Group Corporation, China) were used.

\section{Exfoliation process to obtain few-layer graphene}

Typically, the commercial expandable graphite was rapidly heated to $1000{ }^{\circ} \mathrm{C}$ and maintained for $60 \mathrm{~s}$ under the atmosphere of forming gas $\left(5 \% \mathrm{H}_{2}\right.$ and $\left.95 \% \mathrm{Ar}\right)$. The resulting expanded graphite (EG) was mixed with NMP solvent. Then the fewlayer graphene sheets were exfoliated from the EG via durative sonication (Misonix Sonicator 3000, $700 \mathrm{w}$ power) for $60 \mathrm{~min}$ to form a dark grey solution. After sonication, few-layer graphene (less than 5 layers) was about $20 \mathrm{wt} \%$, while multi-layer graphene (5-10 layers) was about $60 \mathrm{wt} \%$, and the remaining $20 \mathrm{wt} \%$ was unfully exfoliated graphite flakes. Finally, the solution was centrifuged at $15000 \mathrm{rpm}$ for $7 \mathrm{~min}$ and separated. This process was repeated until $5 \mathrm{mg}$ of solid, pristine graphene sheets were collected, without any heat treatment, surface modification or oxidation process, as shown in Fig. S1.

\section{Solvothermal process to deposit transition metal oxide NPs on the few-layer graphene}

The resulting few-layer graphene sheets $(5 \mathrm{mg})$, iron(III) acetylacetonate, $\mathrm{Fe}(\mathrm{acac})_{3}(0.035 \mathrm{~g}, 0.1 \mathrm{mmol})$, and absolute ethanol
(20 mL) were mixed and magnetically stirred for $30 \mathrm{~min}$. The mixture was then transferred to a closed stainless-steel autoclave with a Teflon-liner ( $25 \mathrm{~mL}$ in total capacity). No gas was introduced and the pressure was autogeneous. The autoclave was heated to $180{ }^{\circ} \mathrm{C}$ and maintained at this temperature for periods ranging from $4 \mathrm{~h}$ to $16 \mathrm{~h}$. Similarly, graphene $/ \mathrm{Mn}_{3} \mathrm{O}_{4}$ and graphene/ $\mathrm{CoO}$ composites were prepared, using $\mathrm{Mn}(\mathrm{acac})_{3}$ $(0.035 \mathrm{~g}, 0.1 \mathrm{mmol})$ and $\mathrm{Co}(\mathrm{acac})_{3}(0.035 \mathrm{~g}, 0.1 \mathrm{mmol})$ in place of $\mathrm{Fe}(\mathrm{acac})_{3}$ as the transition metal precursor. In order to improve the solubility and reactivity of $\mathrm{Mn}(\mathrm{acac})_{3}$ and $\mathrm{Co}(\mathrm{acac})_{3}$, the reaction temperature was increased to $200{ }^{\circ} \mathrm{C}$. For comparison, pure $\mathrm{Fe}_{3} \mathrm{O}_{4}$ and $\mathrm{Mn}_{3} \mathrm{O}_{4}$ NPs were also prepared using the respective metal precursor, under the same conditions but without graphene as substrate.

\section{Structural and properties characterization}

A FEI TECNAI F20 Transmission Electron Microscope (TEM) with EDS and GIF system at an accelerating voltage of $200 \mathrm{kV}$ was used for analysis of the morphology and crystal structure of graphene $/ \mathrm{Fe}_{3} \mathrm{O}_{4}$, graphene $/ \mathrm{Mn}_{3} \mathrm{O}_{4}$, and graphene/CoO composites. ImageJ and Digital Micrograph programs were utilized to analyze the particle size and coating density, based on a few dozen TEM images. Raman spectra were collected with a HORIBA Jobin Yvon LabRAM Raman spectrometer using an $\mathrm{Ar}^{+}$laser (532 nm). Powder X-ray diffraction (PXRD) studies were performed in the $20-70^{\circ} 2 \theta$ range using a Rigaku Ultima IV $\mathrm{X}$-Ray diffraction system with graphite monochromatized $\mathrm{Cu}$ $\mathrm{K} \alpha$ radiation $(1=1.54187 \AA$ ). Particle sizes were estimated using the Rigaku PDXL software suite: PDXL employs the Scherrer method, which uses the full-width at half-maximum (FWHM) of XRD peaks to estimate particle size according to the Scherrer law; PDXL also applies the Williamson-Hall method, which fits peak width of several peaks from small to large angles to estimate particle size and further accounts for surface strain. X-Ray photoelectron spectroscopy (XPS) measurements were carried out using a PHI Quantera Scanning X-ray Microprobe, which used $\mathrm{Al} \mathrm{K}_{\alpha}$ radiation.

\section{Electrochemical measurements}

Five samples, including pristine graphene (6 mg), pure $\mathrm{Mn}_{3} \mathrm{O}_{4}$ NPs $(6 \mathrm{mg})$, graphene $/ \mathrm{Fe}_{3} \mathrm{O}_{4}(6 \mathrm{mg})$, graphene $/ \mathrm{Mn}_{3} \mathrm{O}_{4}$ composite $(6 \mathrm{mg})$ and graphene/ $\mathrm{CoO}(6 \mathrm{mg})$ were separately mixed with conductive carbon black and PVDF in NMP solution in a weight ratio of 8 (sample): 1 (carbon black): 1 (PVDF). The mixture was then pressed onto nickel foam $(1.5 \mathrm{~cm} \times 1.5 \mathrm{~cm})$, dried under reduced pressure at $120^{\circ} \mathrm{C}$ for $10 \mathrm{~h}$ to remove NMP, and finally covered with PTC1 PortHoles ${ }^{\mathrm{TM}}$ Electrochemical Sample Masks $\left(1 \mathrm{~cm}^{2}\right)$. A graphite rod was used as the counter electrode, and a saturated calomel electrode (SCE) served as the reference electrode. All the measurements were carried out in an aqueous $0.5 \mathrm{M} \mathrm{NaCl}$ electrolyte at room temperature. The cyclic voltammetry (CV) and galvanostatic charge-discharge were measured with a Gamry Reference $600^{\mathrm{TM}}$ potentiostat.

\section{Results and discussion}

Monodispersed magnetic iron oxide NPs have been successfully precipitated onto the surfaces of exfoliated graphene by a simple 

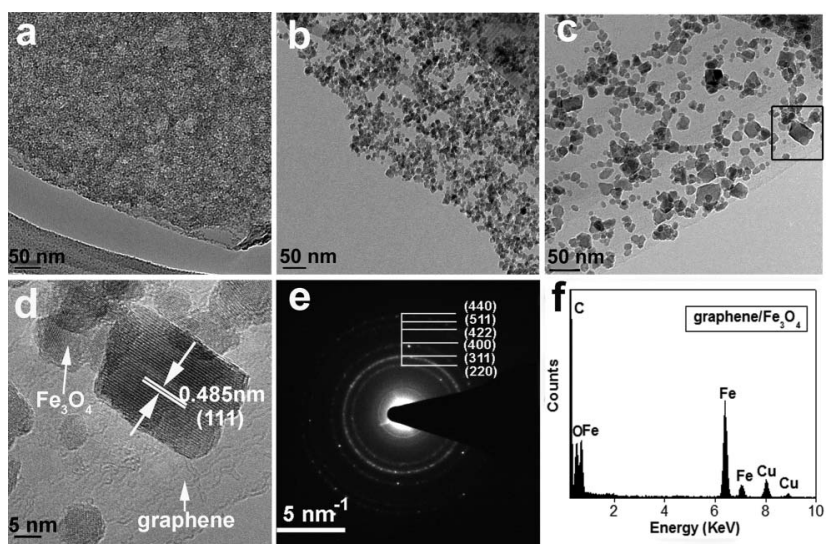

Fig. 1 TEM analysis of graphene $/ \mathrm{Fe}_{3} \mathrm{O}_{4}$ composites prepared by solvothermal reaction at $180{ }^{\circ} \mathrm{C}$ at varying reaction times of $4 \mathrm{~h}$ (a), $8 \mathrm{~h}$ (b), and $16 \mathrm{~h} \mathrm{(c);} \mathrm{(d)} \mathrm{HRTEM} \mathrm{image} \mathrm{of} \mathrm{boxed} \mathrm{area} \mathrm{of} \mathrm{(c);} \mathrm{(e)} \mathrm{the}$ corresponding SAED pattern; (f) typical EDS pattern of the attached $\mathrm{Fe}_{3} \mathrm{O}_{4} \mathrm{NPs}$

solvothermal process at a temperature of $180^{\circ} \mathrm{C}$, using iron(III) acetylacetonate and expanded graphite as precursors, and using anhydrous ethanol as the solvent. TEM images (Fig. 1a-c) show the graphene $/ \mathrm{Fe}_{3} \mathrm{O}_{4}$ composites prepared by solvothermal reactions at $180^{\circ} \mathrm{C}$ for $4 \mathrm{~h}(\mathrm{a}), 8 \mathrm{~h}(\mathrm{~b})$, and $16 \mathrm{~h}(\mathrm{c})$, respectively. Magnetic iron oxide NPs were observed to uniformly distribute on the surface of graphene sheets. The particle size and loading density can be tailored by varying reaction time. When the reaction time was only $4 \mathrm{~h}$, small NPs (less than $1 \mathrm{~nm}$ ) coated the graphene stacks, and the coating density was nearly $100 \%$ of the exposed surface. As the reaction time was increased to $8 \mathrm{~h}$, the size of magnetite NPs became larger, with an average size of about $5 \mathrm{~nm}$, and the coating density was decreased to about $90 \%$ of the exposed surface area. When the reaction time was further extended to $16 \mathrm{~h}$, the coating density of NPs further decreased to between $60-70 \%$ of the exposed surface, and the particle size further increased to $5-10 \mathrm{~nm}$. It is worth noting that when the reaction time was extended to $24 \mathrm{~h}$, the particle size did not further increase. To identify the crystalline phase present within the NPs, high resolution (HR) TEM was used. A representative HRTEM image of the $16 \mathrm{~h}$ reaction product is shown in Fig. 1d, which demonstrated that the attached $\mathrm{Fe}_{3} \mathrm{O}_{4}$ NPs were well crystallized and that the lattice spacing between two adjacent crystal planes was about $0.485 \mathrm{~nm}$; this distance is consistent with the (111) lattice spacing of cubic, inverse spinel $\mathrm{Fe}_{3} \mathrm{O}_{4}$. The corresponding selected area electron diffraction (SAED) pattern taken from the graphene $/ \mathrm{Fe}_{3} \mathrm{O}_{4}$ composite showed multiple diffraction rings belonging to the cubic inverse spinel $\mathrm{Fe}_{3} \mathrm{O}_{4}$ phase, assigned to the expected crystalline reflections of (220), (311), (400), (422), (511) and (440), respectively, as shown in Fig. 1e. Elemental identification of the particles was achieved using energy-dispersive X-ray spectroscopy (EDS). The spectrum shown in Fig. 1f revealed the presence of iron and oxygen in the composite $(\mathrm{Cu}$ in the spectrum was attributed to the copper TEM grid).

Fig. 2a shows the HRTEM image of a graphene $/ \mathrm{Fe}_{3} \mathrm{O}_{4}$ hybrid prepared at $180^{\circ} \mathrm{C}$ for $8 \mathrm{~h}$. The lattice fringes of well-crystallized $\mathrm{Fe}_{3} \mathrm{O}_{4}$ NPs, the obvious graphene edges and even the planar graphene hexagonal lattice can be clearly observed (the enlarged

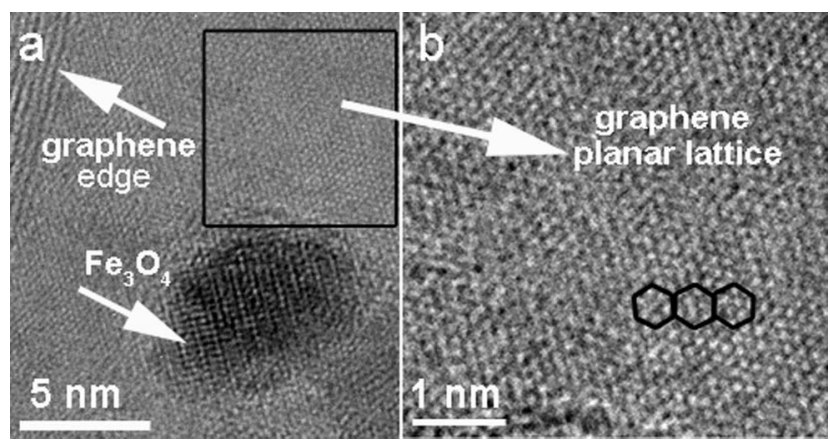

Fig. 2 (a) HRTEM image of a graphene $/ \mathrm{Fe}_{3} \mathrm{O}_{4}$ hybrid prepared at $180^{\circ} \mathrm{C}$ for $8 \mathrm{~h}$; (b) enlarged image of boxed area in (a).

HRTEM image of the boxed area in Fig. 2a is shown in Fig. 2b). It is interesting to notice that although the image was taken with an accelerating voltage of $200 \mathrm{kV}$, the planar lattice of graphene can still be observed. The distinctive lattice structure unambiguously confirmed that the high-quality graphene sheets maintained their structural integrity without having significant defects after chemical processing of depositing the $\mathrm{Fe}_{3} \mathrm{O}_{4} \mathrm{NPs}$.

Raman spectroscopy has been accepted as a very versatile, purely optical, high-throughput technique for evaluating structural defects, number of layers, and doping level of graphene. The Raman spectrum of graphene is dominated by three main features, G-, D-, and 2D- Raman modes, each having different physical origins. The peak at $\sim 1580 \mathrm{~cm}^{-1}$ ( $\mathrm{G}$ band), arising from emission of zone-center optical phonons, corresponds to the doubly degenerate $\mathrm{E}_{2 g}$ mode of graphite, and is related to the coplanar vibration of $\mathrm{sp}^{2}$-bonded carbon atoms. The peak at $\sim 1350 \mathrm{~cm}^{-1}$ (D band) is assigned to graphene defects and disorders. The peak at $\sim 2700 \mathrm{~cm}^{-1}$ (2D) is assigned to secondorder zone boundary phonons. Fig. 3 shows the Raman spectra of pure $\mathrm{Fe}_{3} \mathrm{O}_{4} \mathrm{NPs}$, pristine graphene and the graphene $/ \mathrm{Fe}_{3} \mathrm{O}_{4}$ composite. For the sample of $\mathrm{Fe}_{3} \mathrm{O}_{4} \mathrm{NPs}$ only, the spectrum shows peaks at 300,370, 560 and $1290 \mathrm{~cm}^{-1}$, all of which are typical of iron oxide, and consistent with the reported references. ${ }^{25,26}$ For the sample of pristine graphene, the intensity

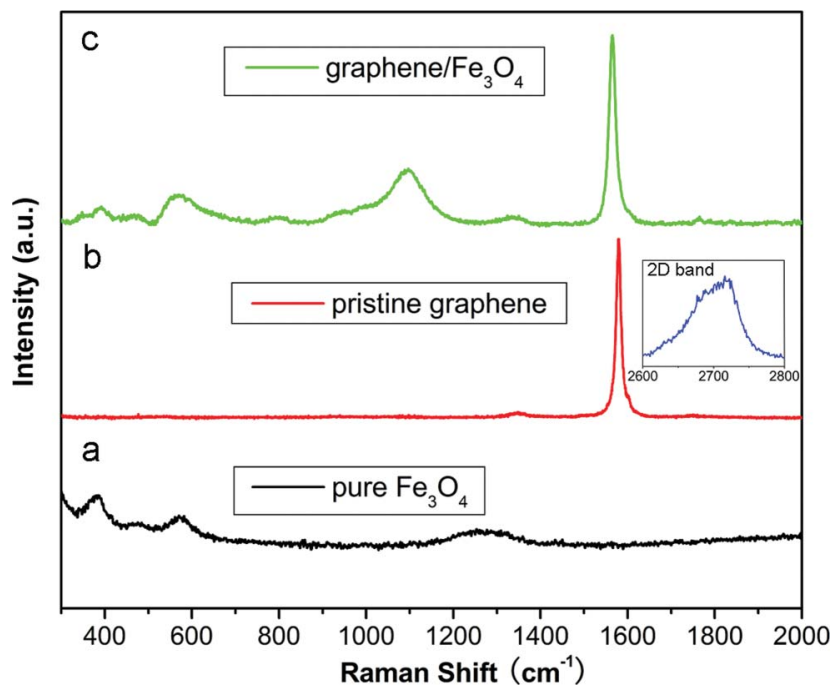

Fig. 3 Raman spectra of (a) pure $\mathrm{Fe}_{3} \mathrm{O}_{4} \mathrm{NPs}$, (b) pristine graphene and (c) graphene $/ \mathrm{Fe}_{3} \mathrm{O}_{4}$ composite. 
ratio of the $D$ to $G$ band $\left(I_{D} / I_{G}=0.053\right)$ is very small, reflecting the very low defect density of graphene. Also, the line shape of $2 \mathrm{D}$ band (Fig. 3b, inset) is in good agreement with the results of five-layer graphene. ${ }^{27}$ For the graphene $/ \mathrm{Fe}_{3} \mathrm{O}_{4}$ composite sample, the two main peaks at 370 and $560 \mathrm{~cm}^{-1}$ from $\mathrm{Fe}_{3} \mathrm{O}_{4}$ remain unchanged, and this can be explained by the noncovalent interaction between graphene and attached $\mathrm{Fe}_{3} \mathrm{O}_{4}$. Moreover, both the peaks of D band $\left(1340 \mathrm{~cm}^{-1}\right)$ and $\mathrm{G}$ band $\left(1563 \mathrm{~cm}^{-1}\right)$ were slightly shift due to the loading of $\mathrm{Fe}_{3} \mathrm{O}_{4} \mathrm{NPs}$, but the intensity ratio remained almost unchanged, indicating preservation of the well-crystallized structure of graphene after deposition of magnetic NPs, which is important for achieving good electrical conductivity in the composites.

Based on the experimental results of different controlled reaction times, a plausible reaction mechanism for decorating the high-quality graphene with $\mathrm{Fe}_{3} \mathrm{O}_{4} \mathrm{NPs}$ is proposed in Scheme 1. First, a metal acetylacetonate precursor, $\mathrm{Fe}(\mathrm{acac})_{3}$ is rapidly decomposed at elevated temperature, producing some reduced $\mathrm{Fe}^{2+}$ and leaving some unreduced $\mathrm{Fe}^{3+}$ cations that coalesce into molecular magnetite monomers ${ }^{28,29}$ in the presence of the reducing solvent (anhydrous ethanol). Second, due to the very high surface energy, these very fine $\mathrm{Fe}_{3} \mathrm{O}_{4}$ seeds are preferentially adsorbed onto the graphene surface, leading to an initial hybrid of graphene sheets with attached $\mathrm{Fe}_{3} \mathrm{O}_{4}$ seed particles. Third, these nuclei gather the neighbouring seeds by attractive van der Waals forces and magnetic dipolar interactions. ${ }^{28}$ Finally, via in situ growth, the seeds form into monodisperse, spherical magnetite NPs. Based on the enlarged particle size with increasing reaction time (from $4 \mathrm{~h}$ to $16 \mathrm{~h}$ ), it suggests that the growth kinetics are typical of Ostwald ripening - that is, small particles tend to dissolve and finally form large particles. These experimental results demonstrate that one-step in situ growth of $\mathrm{Fe}_{3} \mathrm{O}_{4}$ NPs on graphene surfaces both inhibits the stacking of graphene sheets and keeps the NPs from agglomerating to a bigger size, even when the reaction time surpasses $16 \mathrm{~h}$. In this work, we select EG as carbon source because EG has fewer oxygen-containing functional groups compared with graphene oxide, therefore would contain less epoxide, hydroxyl, carbonyl and carboxyl groups. The binding energy between NPs and exfoliated graphene should be lower than chemical bonds, but higher than the van der Waals force. Detailed theoretical

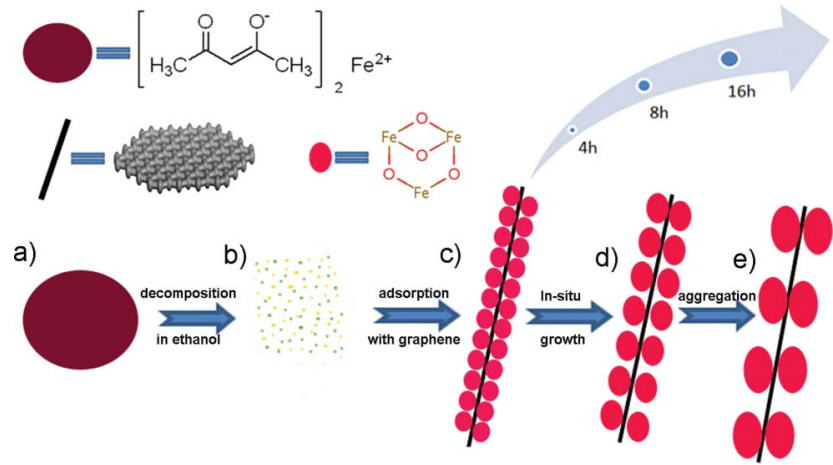

Scheme 1 Schematic illustration of the whole reaction process: (a) $\mathrm{Fe}(\mathrm{acac})_{3}$ precursor; (b) decomposition of $\mathrm{Fe}(\mathrm{acac})_{3}$ into $\mathrm{Fe}^{2+}$ and $\mathrm{Fe}^{3+}$ cations; (c) initial nucleation of NPs and adsorption by graphene; (d) in situ growth to form monodisperse NPs on the surface of the graphene; (e) form larger NPs by Ostwald ripening. simulation is underway, in order to investigate the binding energy and charge-transfer interaction between metal oxide clusters and graphene.

The same process can also be used to produce other transition metal oxide NPs, such as $\mathrm{Mn}_{3} \mathrm{O}_{4}$ (Fig. 4) and $\mathrm{CoO}$ (Fig. 5), hybridized with graphene by using manganese(III) acetylacetonate or cobalt(III) acetylacetonate in lieu of the $\mathrm{Fe}(\mathrm{III})$ precursor. Fig. $4 \mathrm{a}-\mathrm{c}$ shows images of the graphene/ $\mathrm{Mn}_{3} \mathrm{O}_{4}$ composites prepared by the parallel solvothermal process at $200{ }^{\circ} \mathrm{C}$ for $4 \mathrm{~h}, 8 \mathrm{~h}$ and $16 \mathrm{~h}$, respectively. The loading density is decreased from $100 \%$ to $70 \%$ and further to $50-60 \%$. These results indicate that the particle size increased from $2 \mathrm{~nm}$ to $10 \mathrm{~nm}$ to $25 \mathrm{~nm}$ with longer reaction times. HRTEM image confirmed that the attached $\mathrm{Mn}_{3} \mathrm{O}_{4}$ NPs were well crystallized, and that the lattice spacing was about $0.25 \mathrm{~nm}$ and $0.29 \mathrm{~nm}$ (Fig. 4d), which correspond to the (211) and (200) planes of the tetragonal Hausmannite $\mathrm{Mn}_{3} \mathrm{O}_{4}$ phase. The lattice fringes of graphene were also clearly observed, and the number of graphene layers was about 4-5 layers. The SAED image (Fig. 4e) shows the diffraction rings from the (Hausmannite) $\mathrm{Mn}_{3} \mathrm{O}_{4}$ phase, with the expected (112), (211), (220), (105), and (321) planes. Fig. 4f shows the typical EDS pattern of attached $\mathrm{Mn}_{3} \mathrm{O}_{4} \mathrm{NPs}$, confirming the presence of Mn and O. Similarly, Fig. 5a-d shows the TEM images of graphene/ $\mathrm{CoO}$ composites that were prepared at $200{ }^{\circ} \mathrm{C}$ for $6 \mathrm{~h}$ and $12 \mathrm{~h}$. The loading density is decreased from $90 \%$ to $30-40 \%$. HRTEM image indicated the lattice spacing to be about 0.25 $\mathrm{nm}$, which could be indexed to the (111) plane of the cubic rock salt $\mathrm{CoO}$ phase. The corresponding SAED also confirmed that the deposited NPs were $\mathrm{CoO}$ and EDS analysis revealed the presence of the elements $\mathrm{C}, \mathrm{Co}$, and $\mathrm{O}$ belonging to the sample.

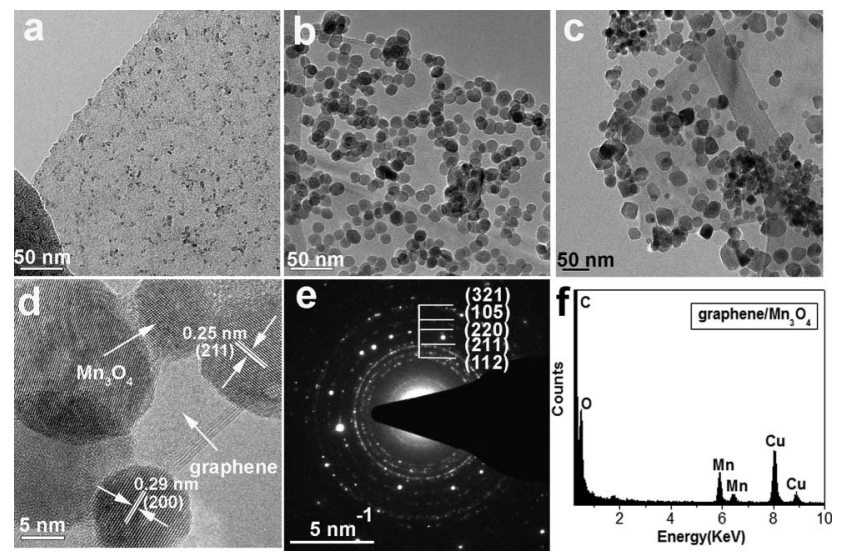

Fig. 4 TEM analysis of graphene/ $\mathrm{Mn}_{3} \mathrm{O}_{4}$ composites prepared by solvothermal reaction at $200{ }^{\circ} \mathrm{C}$. (a)-(c) show products prepared at reaction times of $4 \mathrm{~h}(\mathrm{a}), 8 \mathrm{~h}$ (b), and $16 \mathrm{~h}$ (c), respectively; (d-e) HRTEM image of attached $\mathrm{Mn}_{3} \mathrm{O}_{4} \mathrm{NPs}$ (d) and the corresponding SAED pattern (e); (f) EDS pattern of the attached $\mathrm{Mn}_{3} \mathrm{O}_{4}$ NPs.

Fig. 6 shows the powder X-ray diffraction (XRD) patterns of the pristine exfoliated graphene, the as-prepared graphene $/ \mathrm{Fe}_{3} \mathrm{O}_{4}$, graphene $/ \mathrm{Mn}_{3} \mathrm{O}_{4}$ and graphene/CoO composites. The XRD reflections due to pristine exfoliated graphene at $2 \theta=26.4^{\circ}$ and $54.5^{\circ}$ could be assigned to the (002) and (004) planes of hexagonal graphite (JCPDS card no. 00-41-1487). For comparison, the sample of graphene/ $\mathrm{Fe}_{3} \mathrm{O}_{4}$ showed five additional strong diffraction peaks at $2 \theta=30.2^{\circ}, 35.7^{\circ}, 43.4^{\circ}$, 


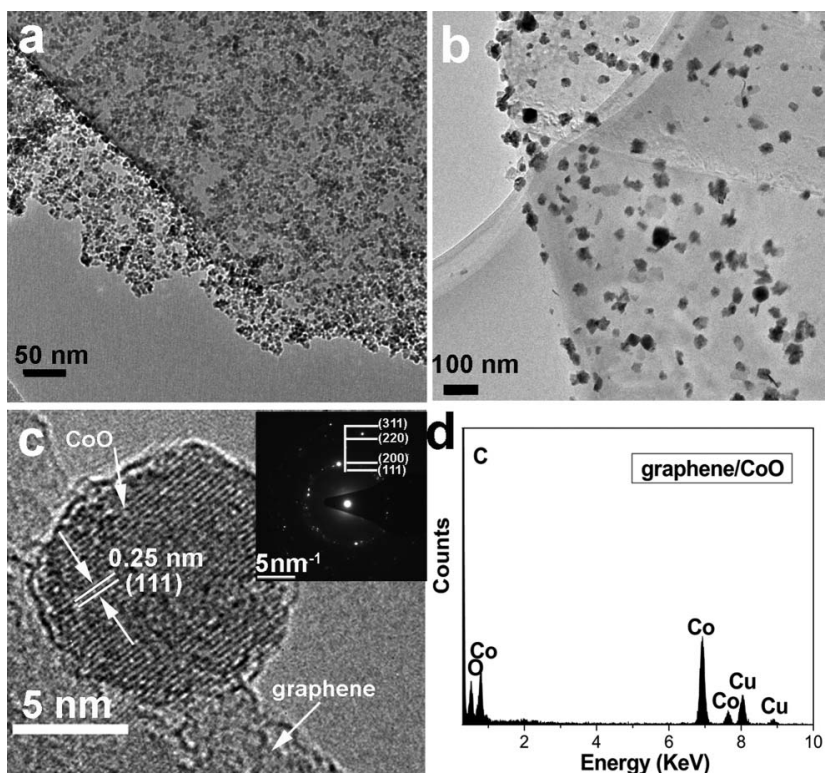

Fig. 5 TEM analysis of graphene/CoO composites prepared by solvothermal reaction at $200{ }^{\circ} \mathrm{C}$. (a)-(b) show products from reaction times of $8 \mathrm{~h}$ and $16 \mathrm{~h}$ respectively; (c) HRTEM image of deposited CoO NPs and the corresponding SAED pattern (inset); (d) typical EDS pattern of the deposited $\mathrm{CoO}$ NPs.

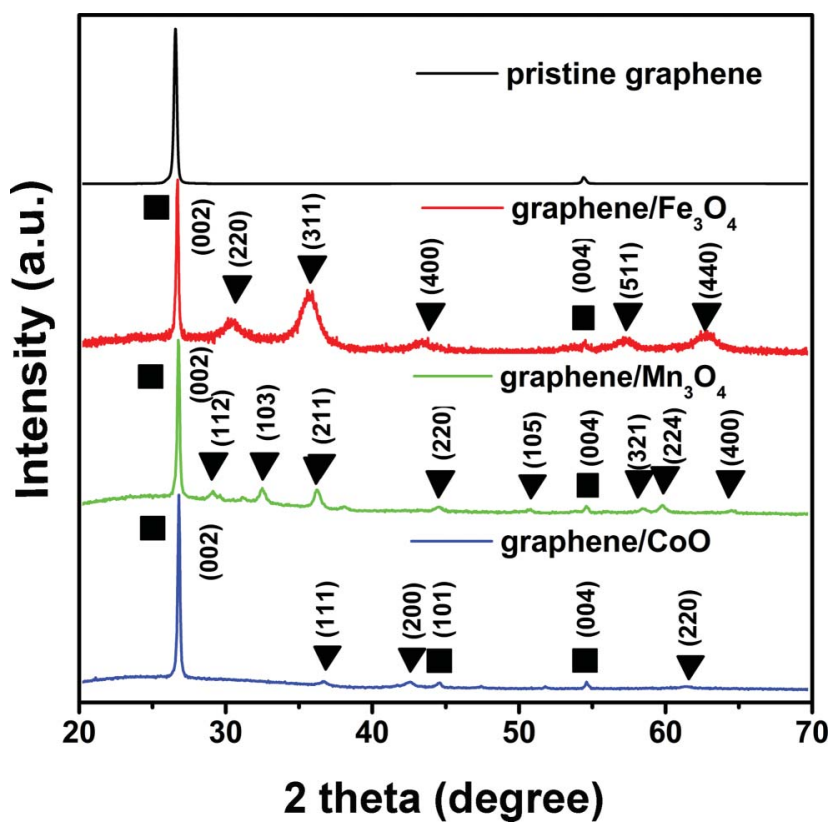

Fig. 6 The XRD patterns of exfoliated pristine graphene, graphene $/ \mathrm{Fe}_{3} \mathrm{O}_{4}$, graphene $/ \mathrm{Mn}_{3} \mathrm{O}_{4}$, and graphene/ $\mathrm{CoO}$ composites, respectively.

$57.3^{\circ}$ and $62.9^{\circ}$, which can be indexed with the (220), (311), (400), (511), and (440) planes (labelled as "₹"), respectively, of the cubic inverse spinel phase (JCPDS card no. 03-653107). In addition, the peak breadth of the $\mathrm{Fe}_{3} \mathrm{O}_{4}$ contributions to the XRD pattern indicated that the attached $\mathrm{Fe}_{3} \mathrm{O}_{4}$ NPs were relatively small. Using the Scherrer and WilliamsonHall methods (in PDXL software) to calculate the average size of the resulting magnetite crystallites gave an estimated size of between 5 and $6 \mathrm{~nm}$, which is consistent with the results observed by TEM images. Furthermore, XPS spectra of graphene $/ \mathrm{Fe}_{3} \mathrm{O}_{4}$ composite samples (Fig. S2) confirmed that the attached NPs were $\mathrm{Fe}_{3} \mathrm{O}_{4}$ in composition. ${ }^{30,31}$ Similarly, for the graphene $/ \mathrm{Mn}_{3} \mathrm{O}_{4}$ sample, the diffraction peaks could be indexed as (112), (103), (211), (220), (105), (321), (224) and (400) planes

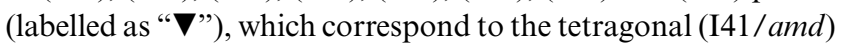
$\mathrm{Mn}_{3} \mathrm{O}_{4}$ (Hausmannite) structure (JCPDS card no. 00-24-0734); For the graphene/CoO sample, the diffraction peaks could be indexed to the (111), (200), and (220) planes (labelled as " $\nabla$ "), which correspond to the cubic rock salt $(\mathrm{Fm}-3 \mathrm{~m}) \mathrm{CoO}$ phase (JCPDS card no. 01-78-0431). Furthermore, it is important to note that there were no heavy metal residuals in final product, which meet the standard of green chemical synthesis.

In order to investigate the specific capacitance of graphene $/ \mathrm{Fe}_{3} \mathrm{O}_{4}$, graphene $/ \mathrm{Mn}_{3} \mathrm{O}_{4}$ and graphene/CoO composites, cyclic voltammetry $(\mathrm{CV})$ analysis was performed at a scan rate of $10 \mathrm{mV} \mathrm{s}^{-1}$ in the potential range of $0.0-1.0 \mathrm{~V}$, with $0.5 \mathrm{M} \mathrm{NaCl}$ neutral aqueous electrolyte, as shown in Fig. $7 \mathrm{a}$. From the CV curves, we can see that the current density of high-quality graphene-based composites reached as high as 4.5-5.5 $\mathrm{A} \mathrm{g}^{-1}$, which is much higher than that of $\mathrm{GO}^{18,19}$ or reduced $\mathrm{GO}^{16}$ based composites. Furthermore, we measured the sheet resistance of exfoliated graphene sheet by a four-probe instrument, and the resistance was about $850 \Omega$ /sq (Fig. S3), at least three orders of magnitude less than reduced GO, ${ }^{32,33}$ which indicated the low-defect exfoliated graphene acted as an excellent conductive substrate for electron transfer. The specific capacitance of the composite electrode can be calculated based on the following equation:

$$
C=\frac{1}{\omega v\left(V_{c}-V_{a}\right)} \int_{V_{a}}^{V_{c}} I(V) d V
$$

where $C$ is the specific capacitance, $\omega$ is the mass of sample in the working electrode $(\mathrm{g}), v$ is the potential scan rate $\left(\mathrm{mV} \mathrm{s}^{-1}\right), V_{c^{-}}$ $V_{a}$ is the sweep potential range, and $I(V)$ is the current density
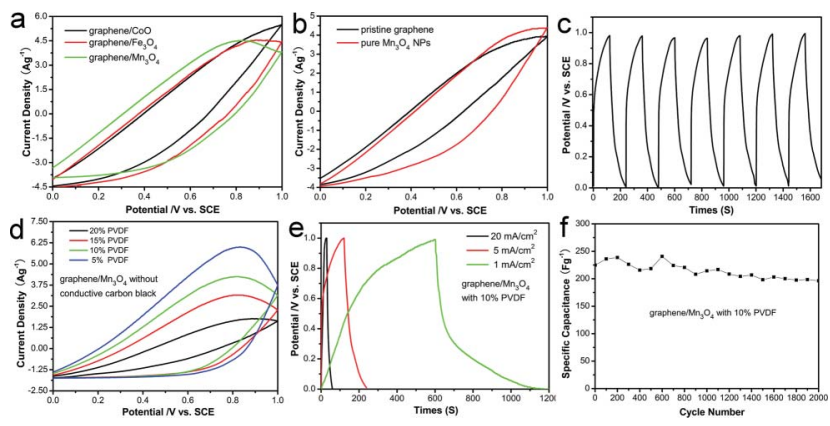

Fig. 7 (a) Cyclic voltammetry (CV) curves of graphene $/ \mathrm{Fe}_{3} \mathrm{O}_{4}$, graphene $/ \mathrm{Mn}_{3} \mathrm{O}_{4}$ and graphene $/ \mathrm{CoO}$ composites, at a scan rate of $10 \mathrm{mV} \mathrm{s}^{-1}$ in $0.5 \mathrm{M} \mathrm{NaCl}_{(a q)}$; (b) $\mathrm{CV}$ curves of pristine graphene and pure $\mathrm{Mn}_{3} \mathrm{O}_{4} \mathrm{NPs}$ at a scan rate of $10 \mathrm{mV} \mathrm{s}^{-1}$ in $0.5 \mathrm{M} \mathrm{NaCl}_{(a q)}$; (c) Galvanostatic charge-discharge curve of a graphene $/ \mathrm{Mn}_{3} \mathrm{O}_{4}$ composite at a current density of $2 \mathrm{~A} \mathrm{~g}^{-1}$ in $0.5 \mathrm{M} \mathrm{NaCl}_{(a q)}$; (d) $\mathrm{CV}$ curves of graphene $/ \mathrm{Mn}_{3} \mathrm{O}_{4}$ composites without any conductive carbon black but with different ratio of PVDF as binder, at a scan rate of $10 \mathrm{mV}$ $\mathrm{s}^{-1}$ in $0.5 \mathrm{M} \mathrm{NaCl}_{(a q)}$; (e) Galvanostatic charge-discharge curve of a graphene $/ \mathrm{Mn}_{3} \mathrm{O}_{4}$ composite at a current density of $1 \mathrm{~mA} \mathrm{~cm}{ }^{-2}, 5$ $\mathrm{mA} \mathrm{cm}{ }^{-2}$ and $20 \mathrm{~mA} \mathrm{~cm}^{-2}$ in $0.5 \mathrm{M} \mathrm{NaCl}_{(a q)}$; (f) Long-term cycling performance of a graphene $/ \mathrm{Mn}_{3} \mathrm{O}_{4}$ composite with $10 \mathrm{wt} \%$ PVDF. 
$\left(\mathrm{A} \mathrm{cm}^{-2}\right){ }^{34}$ The calculated capacitance of graphene $/ \mathrm{Fe}_{3} \mathrm{O}_{4}$, graphene $/ \mathrm{Mn}_{3} \mathrm{O}_{4}$ and graphene $/ \mathrm{CoO}$ reached $213.0 \mathrm{~F} / \mathrm{g}, 239.6$ $\mathrm{F} / \mathrm{g}$ and $149.1 \mathrm{~F} / \mathrm{g}$, respectively. For comparison, the $\mathrm{CV}$ curves of pristine graphene and pure $\mathrm{Mn}_{3} \mathrm{O}_{4}$ NPs (Fig. S4) were also investigated (Fig. 7b), which were only $98.2 \mathrm{~F} / \mathrm{g}$ and 141.4 $\mathrm{F} / \mathrm{g}$. The results indicate that novel graphene-based hybrid nanostructure takes the synergetic effect of both components. Firstly, the well-dispersed $\mathrm{Mn}_{3} \mathrm{O}_{4}$ NPs on graphene (as shown in Fig. 4a-b) could effectively prevent the stacking of graphene sheets which leads to higher available surface areas for the storage of charge; Secondly, high-quality exfoliated graphene (as shown in Fig. 2a-b), as conductive substrate, can not only provide the efficient electron transfer channels for $\mathrm{Mn}_{3} \mathrm{O}_{4}$, but also contribute double-layer capacitance to the overall energy storage; Thirdly, the surfactant-free interfacial contact between $\mathrm{Mn}_{3} \mathrm{O}_{4}$ and graphene sheets can facilitate accessibility of electrolyte ions and shorten the ion diffusion path. ${ }^{35,36} \mathrm{It}$ is reasonable to suggest that the improved capacitance can be attributed to the high coating density with uniform particle distribution, the high-quality exfoliated graphene, as well as the clean interface between the graphene and attached NPs. To gain a better understanding of the graphene $/ \mathrm{Mn}_{3} \mathrm{O}_{4}$ composites as possible electrode materials for supercapacitors, a galvanostatic charge-discharge curve was also measured in $0.5 \mathrm{M} \mathrm{NaCl}$ within voltage window of $0.0-1.0 \mathrm{~V}$ (vs. SCE) at a current density of $2.0 \mathrm{~A} \mathrm{~g} \mathrm{~g}^{-1}$, as shown in Fig. 7c. From the chargedischarge curve, we can see that the potentials of chargedischarge lines are nearly proportional to the charge or discharge time in the neutral $\mathrm{NaCl}$ electrolyte, which indicates rapid $I-V$ response. ${ }^{19}$

Usually, during the process of supercapacitor electrode fabrication, a certain amount of conductors (conductive carbon black) and binders (PVDF) need to be added. In order to prove graphene itself can provide a direct conductive path for $\mathrm{Mn}_{3} \mathrm{O}_{4} \mathrm{NPs}$, we fabricated graphene $/ \mathrm{Mn}_{3} \mathrm{O}_{4}$ electrode only with different ratios of PVDF ( $5 \mathrm{wt}^{\mathrm{t}} \%, 10 \mathrm{wt} \%, 15 \mathrm{wt} \%$ and $20 \mathrm{wt} \%$ ) as the binder, without the addition of conductive carbon black, then measured the corresponding CV curves (Fig. 7d), at a scan rate of $10 \mathrm{mV} \mathrm{s}^{-1}$ in the potential range of $0.0-1.0 \mathrm{~V}$ with $0.5 \mathrm{M} \mathrm{NaCl}$ neutral aqueous electrolyte. The calculated capacitance reached $323.4 \mathrm{~F} / \mathrm{g}, 241.0 \mathrm{~F} / \mathrm{g}, 182.7 \mathrm{~F} / \mathrm{g}$ and $72.1 \mathrm{~F} / \mathrm{g}$, respectively. Although the specific capacitance of graphene $/ \mathrm{Mn}_{3} \mathrm{O}_{4}$ with $5 \mathrm{wt} \% \mathrm{PVDF}$ reaches $323.4 \mathrm{~F} / \mathrm{g}$, the cycling stability is not very good. The electrode membrane of graphene $/ \mathrm{Mn}_{3} \mathrm{O}_{4}$ composite would fall off from nickel foam after several cycles of $\mathrm{CV}$ sweep due to the deficiency of PVDF binders. It is suggested that adding $10 \mathrm{wt} \% \mathrm{PVDF}$ as binder is the balance between capacitance and cycling stability. In addition, the $\mathrm{CV}$ curves showed excellent current density of $1.25 \mathrm{~A} \mathrm{~g} \mathrm{~g}^{-1}$, even though the ratio of PVDF is as high as $20 \mathrm{wt} \%$, which indicated the high graphitization degree of graphene. Galvanostatic charge-discharge curves (Fig. 7e) were also carried out on the graphene $/ \mathrm{Mn}_{3} \mathrm{O}_{4}$ composite with $10 \mathrm{wt} \%$ PVDF at different current densities of $1 \mathrm{~mA} \mathrm{~cm}^{-2}, 5 \mathrm{~mA} \mathrm{~cm}$ and $20 \mathrm{~mA} \mathrm{~cm}^{-2}$, respectively. From the charge-discharge curve, we can also see that the potentials of charge-discharge lines are nearly proportional to the charge or discharge time in the neutral $\mathrm{NaCl}$ electrolyte, especially in the high current density of $5 \mathrm{~mA} \mathrm{~cm}^{-2}$ and $20 \mathrm{~mA} \mathrm{~cm}^{-2}$, but not ideal in low current density of $1 \mathrm{~mA} \mathrm{~cm}{ }^{-2}$. The specific discharge capacitance $\left(C_{\mathrm{s}}\right)$ can be calculated according to the discharge curves:

$$
C_{\mathrm{s}}=I \times \Delta t /(\Delta V \times m),
$$

where $I$ is the constant discharge current, $\Delta t$ is the discharge time, $m$ is active mass and $\Delta V$ is the potential drop during discharge. ${ }^{16}$ The long-term cycling stability of graphene $/ \mathrm{Mn}_{3} \mathrm{O}_{4}$ composite with $10 \mathrm{wt} \% \mathrm{PVDF}$ as binder was also evaluated by cyclic charge-discharge test over 2000 cycles (Fig. 7f). After 600 cycles, the specific capacitance increased by $6.25 \%$ instead of decreasing. After 2000 cycles, the total decrease was about 12.6\% of initial capacitance, which indicated a good cycling stability of graphene $/ \mathrm{Mn}_{3} \mathrm{O}_{4}$ for potential supercapacitor applications. Briefly speaking, utilizing high-conductive graphene as substrate eliminated the need of conductive carbon black as fillers, as well as improved the specific capacitance and cycling stability.

\section{Conclusions}

We report a simple, general and environmentally-friendly synthetic route that affords high-quality exfoliated graphene sheets coated with transition metal oxide NPs, including $\mathrm{Fe}_{3} \mathrm{O}_{4}, \mathrm{Mn}_{3} \mathrm{O}_{4}$ and $\mathrm{CoO}$ NPs, by decomposition of the tris(acetylacetonate) $\mathrm{M}(\mathrm{III})(\mathrm{M}=\mathrm{Fe}, \mathrm{Mn}, \mathrm{Co}$ ) precursor in ethanol, using expanded graphite as the starting material. The entire process was free of surfactants and stabilizers, and thus resulted in the intrinsic conductivity of the graphene being preserved, as well as high charge-accumulating ability of the transition metal oxide NPs. CV and galvanostatic charge-discharge curves demonstrated the increased capacitance of $239.6 \mathrm{~F} / \mathrm{g}$ and high current density of $4.5 \mathrm{~A} \mathrm{~g} \mathrm{~g}^{-1}$ in neutral electrolyte for graphene $/ \mathrm{Mn}_{3} \mathrm{O}_{4}$ composite. Furthermore, the high electrical conductivity of graphene eliminates the need for conductive carbon black. The increased capacitance and high current density can be largely attributed to a high coating density of attached NPs with uniform distribution, the excellent electrical conductivity of graphene, and the surfactant-free interface between graphene and attached NPs. This method opens opportunities to achieve the large-scale production of graphene-based composites, which could lead to their promising applications in green energy-related electrochemical devices.

\section{Notes and references}

1 W. F. Wei, X. W. Cui, W. X. Chen and D. G. Ivey, Chem. Soc. Rev., 2011, 40, 1697

2 C. C. Hu, Y. T. Wu and K. H. Chang, Chem. Mater, 2008, 20, 2890.

3 M. Toupin, T. Brousse and D. Belanger, Chem. Mater, 2004, 16, 3184.

4 T. Cottineau, M. Toupin, T. Delahaye, T. Brousse and D. Belanger, Appl. Phys. A: Mater. Sci. Process., 2006, 82, 599.

5 N. L. Wu, S. Y. Wang, C. Y. Han, D. S. Wu and L. R. Shiue, J. Power Sources, 2003, 113, 173.

6 J. R. Miller, R. A. Outlaw and B. C. Holloway, Science, 2010, 329, 1637.

7 D. N. Futaba, K. Hata, T. Yamada, T. Hiraoka, Y. Hayamizu, Y. Kakudate, O. Tanaike, H. Hatori, M. Yumura and S. Iijima, Nat. Mater., 2006, 5, 987.

8 E. Frackowiak and F. Beguin, Carbon, 2001, 39, 937.

9 Y. W. Zhu, S. Murali, M. D. Stoller, K. J. Ganesh, W. W. Cai, P. J. Ferreira, A. Pirkle, R. M. Wallace, K. A. Cychosz, M. Thommes, D. Su, E. A. Stach and R. S. Ruoff, Science, 2011, 332, 1537. 
10 S. Stankovich, D. A. Dikin, G. H. B. Dommett, K. M. Kohlhaas, E. J. Zimney, E. A. Stach, R. D. Piner, S. T. Nguyen and R. S. Ruoff, Nature, 2006, 442, 282.

11 A. K. Geim and K. S. Novoselov, Nat. Mater., 2007, 6, 183.

12 X. Du, I. Skachko, A. Barker and E. Y. Andrei, Nat. Nanotechnol., 2008, 3, 491.

13 H. L. Wang, L. F. Cui, Y. A. Yang, H. S. Casalongue, J. T. Robinson, Y. Y. Liang, Y. Cui and H. J. Dai, J. Am. Chem. Soc., 2010, 132, 13978.

14 H. P. Cong, J. J. He, Y. Lu and S. H. Yu, Small, 2010, 6, 169.

15 H. K. He and C. Gao, ACS Appl. Mater. Interfaces, 2010, 2, 3201.

16 W. H. Shi, J. X. Zhu, D. H. Sim, Y. Y. Tay, Z. Y. Lu, X. J. Zhang, Y. Sharma, M. Srinivasan, H. Zhang, H. H. Hng and Q. Y. Yan, J. Mater. Chem., 2011, 21, 3422.

17 B. J. Li, H. Q. Cao, J. Shao, M. Z. Qu and J. H. Warner, J. Mater. Chem., 2011, 21, 5069.

18 S. Chen, J. W. Zhu, X. D. Wu, Q. F. Han and X. Wang, ACS Nano, 2010, 4, 2822.

19 Z. S. Wu, W. C. Ren, D. W. Wang, F. Li, B. L. Liu and H. M. Cheng, ACS Nano, 2010, 4, 5835.

20 Q. Cheng, J. Tang, J. Ma, H. Zhang, N. Shinya and L.-C. Qin, Carbon, 2011, 49, 2917.

21 V. Georgakilas, V. Tzitzios, D. Gournis and D. Petridis, Chem. Mater, $2005,17,1613$.

22 X. Du, C. Y. Wang, M. M. Chen, Y. Jiao and J. Wang, J. Phys. Chem. $C, 2009,113,2643$
23 H. Zhang, G. P. Cao, Z. Y. Wang, Y. S. Yang, Z. J. Shi and Z. N. Gu, Nano Lett., 2008, 8, 2664.

24 J. Yan, Z. J. Fan, T. Wei, J. Cheng, B. Shao, K. Wang, L. P. Song and M. L. Zhang, J. Power Sources, 2009, 194, 1202.

25 D. Bersani, P. P. Lottici and A. Montenero, J. Raman Spectrosc., 1999, 30, 355.

26 D. L. A. deFaria, S. V. Silva and M. T. deOliveira, J. Raman Spectrosc., 1997, 28, 873.

27 A. C. Ferrari, J. C. Meyer, V. Scardaci, C. Casiraghi, M. Lazzeri, F. Mauri, S. Piscanec, D. Jiang, K. S. Novoselov, S. Roth and A. K. Geim, Phys. Rev. Lett., 2006, 97, 187401.

28 Y. Yin and A. P. Alivisatos, Nature, 2005, 437, 664.

29 S. H. Sun, H. Zeng, D. B. Robinson, S. Raoux, P. M. Rice, S. X. Wang and G. X. Li, J. Am. Chem. Soc., 2004, 126, 273.

30 P. C. J. Graat and M. A. J. Somers, Appl. Surf. Sci., 1996, 100, 36.

31 T. Fujii, F. M. F. de Groot, G. A. Sawatzky, F. C. Voogt, T. Hibma and K. Okada, Phys. Rev. B: Condens. Matter, 1999, 59, 3195.

32 G. Eda, G. Fanchini and M. Chhowalla, Nat. Nanotechnol., 2008, 3, 270.

33 C. Gomez-Navarro, R. T. Weitz, A. M. Bittner, M. Scolari, A. Mews, M. Burghard and K. Kern, Nano Lett., 2007, 7, 3499.

34 X. F. Xie and L. Gao, Carbon, 2007, 45, 2365.

35 W. Chen, Z. L. Fan, L. Gu, X. H. Bao and C. L. Wang, Chem. Commun., 2010, 46, 3905.

36 H. Jiang, L. P. Yang, C. Z. Li, C. Y. Yan, P. S. Lee and J. Ma, Energy Environ. Sci., 2011, 4, 1813. 